\title{
Perfluorooctane sulfonate removal by nanofiltration membrane-the effect and interaction of magnesium ion / humic acid
}

\author{
Changwei Zhao ${ }^{\mathrm{a}, \mathrm{b}, *}$, Chuyang Y. Tang ${ }^{\mathrm{c}}$, Pei $\mathrm{Li}^{\mathrm{d}}$, Pegoraro Adrian ${ }^{\mathrm{b}}$, Guangshuo $\mathrm{Hu}^{\mathrm{a}}$ \\ a State Key Laboratory of Environmental Aquatic Chemistry, Research Center for Eco-Environmental Sciences, Chinese Academy of Sciences, Beijing 100085, \\ China \\ ${ }^{\mathrm{b}}$ School of Engineering and Applied Sciences, Harvard University, 29 Oxford St., Cambridge, MA 02138, USA \\ ${ }^{\mathrm{c}}$ Department of Civil Engineering, University of Hong Kong, Pokfulam, Hong Kong \\ d College of Materials Science and Engineering, Beijing University of Chemical Technology, No.15 Beisanhuandong Road, Chaoyang District, Beijing 100029, \\ China
}

\section{A R T I C L E I N F O}

\section{Article history:}

Received 14 October 2015

Received in revised form

28 November 2015

Accepted 23 December 2015

Available online 5 January 2016

\section{Keywords:}

Nanofiltration

PFOS removal

Interaction

\begin{abstract}
A B S T R A C T
Although the presence of perfluorooctane sulfonate (PFOS) in environmental systems has generated widespread interest, little information is available on PFOS removal from surface water by membrane technology. Herein, a novel nanofiltration membrane (NF270) was investigated so as to remove PFOS. More specifically, the interaction and effect of $\mathrm{Mg}^{2+}$ ion and/or humic acid (HA) in the feed solution on PFOS removal efficiency and total permeate flux were examined. Under $0.8 \mathrm{MPa}$, an improvement in PFOS rejection efficiency from $94.3 \%$ to $99.5 \%$ was observed when the concentration of $\mathrm{Mg}^{2+}$ ion was increased from $0-2 \mathrm{mM}$ in the feed solution. This enhancement is attributed to enhanced size exclusion because PFOS molecules are linked together by $\mathrm{Mg}^{2+}$ ion, as shown by Density Functional Theory (DFT) calculation. The result shows that $\mathrm{Mg}^{2+}$ ion can more easily neutralize two PFOS anion than one PFOS anion on the basis of the Gibbs free energy changes. Conversely, the presence of HA had minimal improvement on PFOS rejection because HA had much weaker ability to bind with PFOS comparing to $\mathrm{Mg}^{2+}$. Consequently, The further interaction between $\mathrm{Mg}^{2+}$ and the carboxylic groups of HA molecule, carboxylic group or amino group of NF270 membrane was also calculated via DFT theory. Corresponding DFT structures and calculation parameters of $\mathrm{Mg}^{2+}$ with different groups were obtained. These findings indicate that the size exclusion mechanism primarily governs PFOS removal by the NF270 membrane. Flux results showed that the co-presence of $\mathrm{Mg}^{2+}$ ion and HA in the feed solution resulted in the most flux reduction, by $70 \%$, that was associated with the thickest fouled layer.
\end{abstract}

(c) 2016 Elsevier B.V. All rights reserved.

\section{Introduction}

Perfluorooctane sulfonate (PFOS) has been widely used as ingredients surfactants, firefighting foams, lubricants and insecticides additives for many industrial, commercial, and consumer practices during the last five decades [1,2]. PFOS is an ubiquitous pollutant in rainwater, surface water, groundwater, and even tap water [3,4]. Its global presence, extreme persistence, bioaccumulative nature and strong toxicity have caused widespread concerns, prompting many environmental agencies around the world to restrict the use of PFOS [5-7]. Nevertheless, its use in some selected consumer application (e.g., semiconductor industry) has been exempted due to the lack of immediate replacement, and

\footnotetext{
* Corresponding author at: State Key Laboratory of Environmental Aquatic Chemistry, Research Center for Eco-Environmental Sciences, Chinese Academy of Sciences, Beijing 100085, China.

E-mail address: zhaocw@rcees.ac.cn (C. Zhao).
}

industrial effluents from such activities will continue to be the main source of the PFOS entering into the environment [8] Available models predict a continuous PFOS concentration rise in remote areas in the next two decades despite a decline of its concentration in surface ocean water in response to the chemical's phase out [8]. The constant presence of PFOS in surface water presents a potential threat to the security of drinking water, thereby raising extensive interest in controlling its occurrence in the environment [9-12].

Nanofiltration (NF) is a pressure-driven membrane filtration process that has intermediate characteristics between reverse osmosis and ultrafiltration. Low operation pressures, environmental friendliness, high retention of multivalent anion, low-moleculeweight organic contaminants (200-1000 Da) etc. as its nature advantages makes NF a promising and attractive technology in the removal of PFOS with high rejection efficiencies of $>90 \%$ from water [13-17]. In previous work, Steinle-Darling found NF membrane could effectively remove PFOS [18]. Appleman et al. also 
indicated NF is effective to remove PFOS more than 95\% [19]. However, the above investigation seldom focused on environmental matrix co-existence effects such as cations and natural organic matter (NOM) on PFOS removal. For instance, divalent cations such as magnesium, calcium ion are commonly present in natural water [20]. Our previous individual calcium research indicated that $\mathrm{Ca}^{2+}$ can interact with PFOS molecule and improved PFOS rejection [21]. Meanwhile, $\mathrm{Mg}^{2+}$ has the potential to alter the interaction between PFOS molecules as well as their interaction with other compounds/materials [22]. Wang and Shih [23] systematically studied the effects of four types of cations $\left(\mathrm{Na}^{+}\right.$, $\mathrm{K}^{+}, \mathrm{Mg}^{2+}$, and $\mathrm{Ca}^{2+}$ ) on the adsorption of PFOS on alumina. The experiment outcomes demonstrated that the PFOS adsorption capacities increased as the ionic strength of the cations increased. The adsorption capacity of PFOS on the alumina decreased as $\mathrm{Ca}^{2+}$ presented in the solution owing to the potential bridging effects of $\mathrm{Ca}^{2+}$ in solution. Subramanian et al. studies indicated $\mathrm{Ca}^{2+}$ and $\mathrm{Mg}^{2+}$ might form complexes with PFO- and the monovalent complexes ( $\mathrm{PFO}-\mathrm{Ca}^{+}$) by matrix experimental analysis [24]. Cheng et al.'s research showed that the effect of cations on the sonochemical degradation rates of PFOX has no significant difference by observation [25]. Humic acid (HA) is the major component of NOM present in natural water and has been recognized as a significant precursor of disinfection by-products [26,27]. On the other hand, HA is also an important contaminants to NF membranes [28]. The presence of HA in the feed water therefore can affect PFOS removal either due to its interaction with PFOS molecules or as an indirect result of membrane fouling [29]. To the best of our knowledge, the effect of co-existing of $\mathrm{Mg}^{2+}$ and HA on PFOS removal performance from surface water has not yet been systematically investigated by the NF separation process.

Presumably, $\mathrm{Mg}^{2+}$ ion could strengthen the cross-linkage between the PFOS molecules, which will change the size,properties of the solutes and thus removal by NF. In addition, $\mathrm{Mg}^{2+}$ could interact with the - $\mathrm{COOH}$ groups of $\mathrm{HA}$ molecule as well as the $\mathrm{COOH}$ and $-\mathrm{NH}_{2}$ group of NF270 membrane material. In this regard, molecule simulation such as Density Functional Theory (DFT) calculation could provide valuable insights into the geometry and bonding of PFOS molecules [30,31]. To the best knowledge of the authors, there has not been any systematic report on the interaction of $\mathrm{Mg}^{2+}$ with PFOS, HA and membrane at the microscopic level. Therefore, extending DFT to analyze $\mathrm{Mg}^{2+}-\mathrm{PFOS}, \mathrm{Mg}^{2+}$ membrane and $\mathrm{Mg}^{2+}-\mathrm{HA}$ interaction could pave the road to the understanding of PFOS removal mechanism.

In this work, we examined the role of $\mathrm{Mg}^{2+}$ ion and $\mathrm{HA}$ on the efficiency of the removal of PFOS from surface water using a NF process. Variation in feed condition (e.g., $\mathrm{Mg}^{2+}$ ion, HA, co-existing of $\mathrm{Mg}^{2+}$ and $\mathrm{HA}$ ) were used to determine the role of $\mathrm{Mg}^{2+}$ and HA in governing PFOS rejection and membrane fouling. Furthermore, from the perspective of quantum chemistry it is the first time to obtain the interaction between $\mathrm{Mg}^{2+}$ and PFOS, HA and membrane material by the DFT method. These results allow us to explain the matrix effect on the PFOS removal and membrane fouling behavior.

\section{Experimental}

\subsection{Materials}

Potassium perfluorooctane-sulfonate (PFOS, 99\%) was purchased from AccuStandard, Inc. (USA). Methanol (HPLC grade), acetonitrile, sodium chloride, sodium bicarbonate and magnesium chloride (analytical grade, > 99\%) were purchased from Fisher Scientific (Hampton, NH). Humic acid (HA, technical grade) obtained from Sigma-Aldrich (St. Louis, MO) was purified [32] and used as a model NOM and organic contaminant. The feed solution were prepared by first dissolving a known amount of PFOS in deionized water, to which known quantities of aqueous magnesium chloride solution were added. The HA concentration of $10 \mathrm{mg} / \mathrm{L}$ is common in water, HA was added to the PFOS or the $\mathrm{Mg}^{2+}$-containing PFOS feed solution to achieve a concentration of $10 \mathrm{mg} / \mathrm{L}$. The resulting solution was stirred for $24 \mathrm{~h}$ to obtain a homogenous solution. The commercial NF filtration membrane (NF270) employed was supplied by DOW FilmTec (Minneapolis, MN). NF270 membrane is composed of an active semi-aromatic piperazine-based polyamide layer supported on a microporous polysulfone layer [33], and the membrane features a pore size of $0.34 \mathrm{~nm}[34]$.

\subsection{PFOS quantification}

A $0.22 \mu \mathrm{m}$ membrane filter needle was used to filter each water sample (the initial $4 \mathrm{~mL}$ mixture was discarded to reduce the effect of membrane adsorption based on PFOS high recovery rate of 0.99.), an ultra-performance liquid chromatography-tandem mass spectrometer (UPLC-MS/MS) was used for analysis PFOS concentration using an UPLC system (Waters Corp., USA) equipped with a C18 column (BEH, particle size $1.7 \mu \mathrm{m}, 2.1 \times 50 \mathrm{~mm}$ i.d., Waters Corp., USA) and an MS system Quattro Premier XE tandem quadrupole mass spectrometer (Waters Corp., USA) with an electrospray ionization source. A binary mixture with ratio of $32 \%$ solvent A (10 mmol/L ammonium acetate in MilliQ water) and $68 \%$ B (100\% acetonitrile) as the mobile phase were applied at a flow rate of $0.15 \mathrm{~mL} / \mathrm{min}$ with $10 \mu \mathrm{L}$ rejection. Selected ion monitoring (SIM, 499- > 80) mode was employed to quantify the analytes with $30 \mathrm{~V}$ cone voltage and $11 \mathrm{eV}$ collision energy.

\subsection{Membrane performance tests}

The PFOS rejection and water flux were assessed on a customassembled setup consisting of CEPA CFII crossflow cells (active membrane area of $140 \mathrm{~cm}^{2}$, GE Osmonics, Minnetonka, MN). The detailed testing procedures have been reported previously [19]. All tests were performed at $25 \pm 1{ }^{\circ} \mathrm{C}$, which was controlled by the circulating water bath. For each test, a PFOS feed solution was introduced into the feed tank. The cross flow rate of $1.5 \mathrm{~L} \mathrm{~min}^{-1}$ of the feed solutions was applied to minimize the effect of concentration polarization $(\operatorname{Re}>4000)$. The permeate samples were collected for PFOS concentration measurement based on flow stability after $2 \mathrm{~h}$ under the each test condition. The PFOS rejection, $R$, was determined as follows:

$R(\%)=\left(1-\frac{C_{\mathrm{p}}}{C_{\mathrm{f}}}\right) \times 100$

where $C_{f}$ and $C_{p}$ are the PFOS solute concentration in the feed and permeate samples, respectively.

The water flux, $J$, was obtained by measuring the volume of permeate that passed through the membrane during a set time as follows:

$J=\Delta V \mid A \Delta t$

where $\Delta V$ is the volume change of permeate during the experiment, $A$ is the membrane area and $\Delta t$ denotes the measuring time change.

\subsection{Membrane characterization}

\subsubsection{Scanning Electron Microscopy (SEM)}

A Hitachi S-3000N scanning electron microscope (Hitachi Ltd. Japan) was used to observe the morphology of the virgin and 
fouled membranes. For sample preparation, the samples were first frozen in liquid nitrogen to obtain fragments that were then sputtered coated with platinum using a Hitachi E-1010 Ion Sputtering device.

\subsubsection{Zeta potential measurement}

The zeta potential of membranes surface was measured by Zetasizer Nano ZS 90 series (Malvern, UK). The concentration at $1 \times 10^{-2} \mathrm{~mol} / \mathrm{L} \mathrm{NaCl}$ solution with ultrapure water at $\mathrm{pH}=7$ was used for each membrane. In this process, a given electric field is applied across the membrane. The weak binding ion of the double layer will be moved in the electric field. Zeta potentials were calculated from the measured electro-osmosis potentials using Smoluchowski equation [35]:

$\zeta=\frac{\mu \cdot K \cdot L}{\varepsilon_{r} \cdot \varepsilon_{0} \cdot E_{z}^{2} \cdot A \cdot\left(\lambda_{b 2}-\lambda_{b 1}\right)}$

Where $L$ is the length of the channel, $K$ is the slope that change in current and time over the linear range, $E_{z}$ is the applied electric field strength, $A$ is the area of the channel, $\lambda_{b 2}-\lambda_{b 1}$ is the difference in channel conductivity between the high and low concentration solution.

\subsubsection{X-ray photoelectron microscopy (XPS)}

The XPS spectra were collected on PHI Quantera SXM Scanning $\mathrm{X}$-ray microprobe. The operating pressure was $4.5 \times 10^{-12} \mathrm{Bar}$ with $\mathrm{Al} \mathrm{Ka}$ X-ray anode radiation source was used as the excitation source ( $h \nu=1486.7 \mathrm{eV}$ ). Curve fittings of $\mathrm{C} 1 \mathrm{~s}$ spectra was analyzed by using XPS peak software. All XPS spectra were referenced with C 1s binding energy at $284.8 \mathrm{eV}$. The XPS spectra were using Shirley-type background to subtract, the Gaussian-Lorentzian peak shape were used after performing background.

\subsection{Density Functional Theory (DFT) calculation}

Gaussion03 (Revision C.01wis2, Gaussian, Inc., Wallingford, CT) was used to perform the DFT calculation. The gradient-corrected Density Functional Theory calculation were optimized using the Becke three-parameter nonlocal exchange functional [36] and the Lee-Yang-Parr correlation functional (i.e., B3LYP) [37]. The geometries of the intermediates were fully optimized without any symmetry constrains. The frequencies were analyzed at the same level to confirm the optimized structures to be ground states without imaginary frequency. In the current study, DFT calculation was employed to study the role of $\mathrm{Mg}^{2+}$ in PFOS interaction with other PFOS molecules, HA and membrane. To avoid excess computational power requirement, HA and membrane are represented by the simplified structures (shown in Fig. 1), HA is composed of two benzene rings with $4-\mathrm{OH}$ and $1-\mathrm{COOH}$ groups and membrane of 1 amino benzene ring connected with a $1-\mathrm{NH}-\mathrm{CO}$ and connection of $2-\mathrm{COOH}$ of benzene ring without sacrificing the chemical nature of the problem according to related chemical composition [38].

\section{Results and discussion}

\subsection{Effect of individual $\mathrm{Mg}^{2+}$ ion / HA on PFOS removal}

Magnesium ion and HA have been found to play an important role in interfacial processes between PFOS molecules and their surrounding environment [39]. In some water system $\mathrm{Mg}^{2+}$ ion or HA is single existence, here firstly investigating the effect of individual $\mathrm{Mg}^{2+}$ ion or HA on PFOS removal efficiency and results is shown in Fig. 2. It is observed (Fig. 2A) that increasing the $\mathrm{Mg}^{2+}$ concentration in the feed solution (100 ppb PFOS) led to a more increase of PFOS rejection (from $94.1 \%$ to $98.6 \%$ at $0.4 \mathrm{MPa}$ ). The one reason is that $\mathrm{Mg}^{2+}$ can bridge and form the complex between $\mathrm{SO}_{3}^{-}$group of PFOS molecule, corresponding the increase in PFOS molecule size. It is agree with the improved PFOS removal efficiency observed owing to prominent sieving mechanism.

In order to explain how $\mathrm{Mg}^{2+}$ concentration affects PFOS complexation, we obtained the PFOS peak position and area during UPLC-MS/MS analysis. In the absence of $\mathrm{Mg}^{2+}$, only a single peak was detected (detection time 1.5-2 min, attributed to unassociated PFOS anion, shown in Fig. 3). When $\mathrm{Mg}^{2+}$ was present, a new peak of detection time 1.0-1.3 min was observed, which can be attributed to the $\mathrm{Mg}^{2+}$ complexed PFOS molecules. As shown in Fig. 3b, it is interesting to observe that the relative PFOS complexation distribution increased with the $\mathrm{Mg}^{2+}$ concentration increase from 0.5 to $2.0 \mathrm{mM}$. That is to say the increasing $\mathrm{Mg}^{2+}$ concentration could induce stronger complexing ability with PFOS. Another, it can also be seen that both zeta potential (shown in Table 1) and PFOS adsorption (shown in Table 2, after the batch experiments involving the investigation of PFOS adsorption tests, the PFOS originally adsorbed on the membranes were desorbed in $50 \%$ (by volume) methanol aqueous solution on a thermostatic shaker at $150 \mathrm{rpm}$ and $25^{\circ} \mathrm{C}$ for $24 \mathrm{~h}$. Then, the concentrations of PFOS were determined using LC-MS/MS.) increased with the increase $\mathrm{Mg}^{2+}$ concentration. This is because the electrostatic attraction between the $\mathrm{Mg}^{2+}$ and negative charges on the membrane surfaces, and the neutralize and bridging both with PFOS and the negatively charged membrane surface corresponding the enhance the attachment of PFOS on the membrane. The above reason may increase the rejection of PFOS for NF270 membrane.

The presence of individual HA (Fig. 2B) resulted in a slight improvement in PFOS rejection efficiency (only from $94.1 \%$ to $95.1 \%$ at $0.4 \mathrm{MPa}$ ) with the increase of HA concentration from $5 \mathrm{mg} / \mathrm{L}$ to $20 \mathrm{mg} / \mathrm{L}$. As shown in Table 1, the zeta potential decreased with the increase of HA concentration, increased little rejection is attributed to enhanced electrostatic exclusion.

\subsection{Effect of co-existence of $\mathrm{Mg}^{2+}$ ion and $\mathrm{HA}$ on PFOS removal}

The co-existence of $\mathrm{Mg}^{2+}$ ion $(1 \mathrm{mM})$ and $\mathrm{HA}(10 \mathrm{mg} / \mathrm{L})$ in the

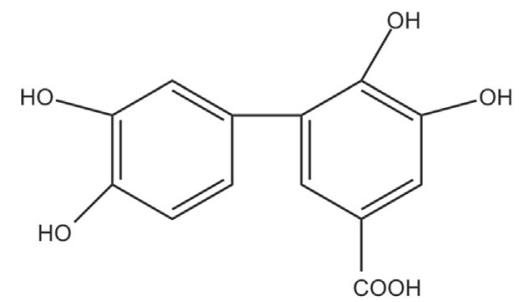

HA<smiles>CCCC(=O)Nc1cccc(NC(=O)c2cc(C(=O)O)cc(C(=O)Nc3cccc(NC(=O)c4cc(C(=O)O)cc(C(=O)O)c4)c3)c2)c1</smiles>

NF270 membrane

Fig. 1. The simplified structures of HA and NF270 membrane. 

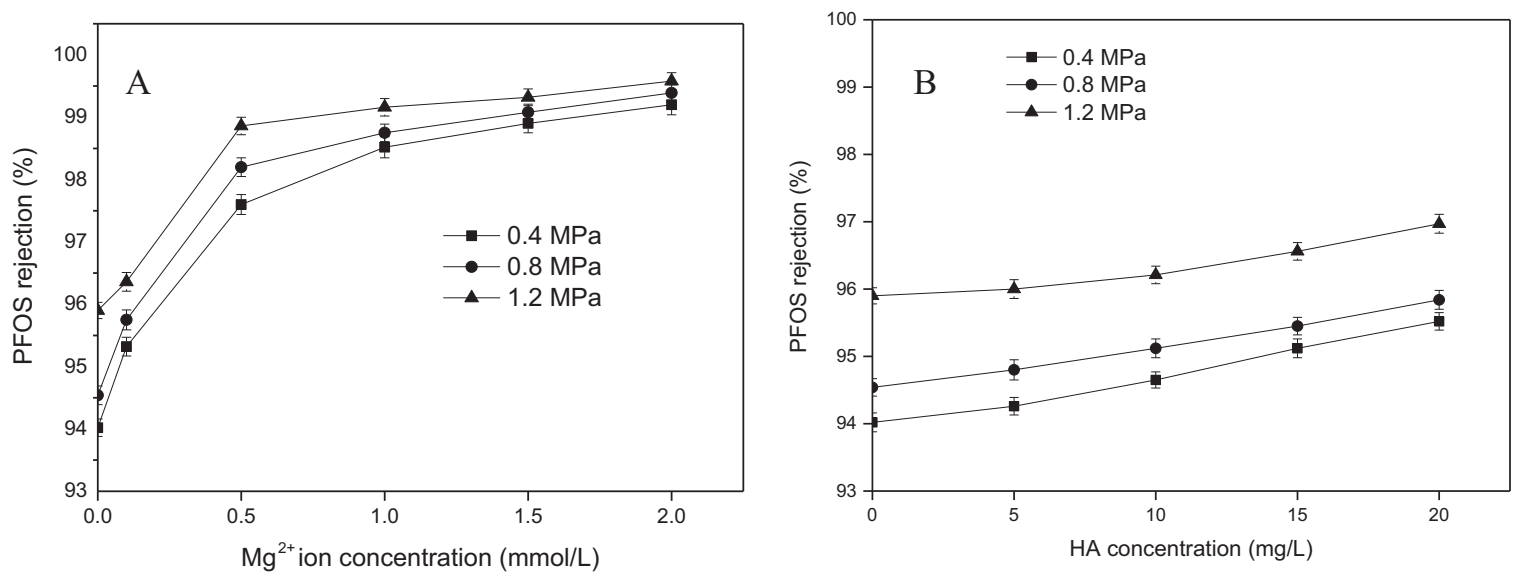

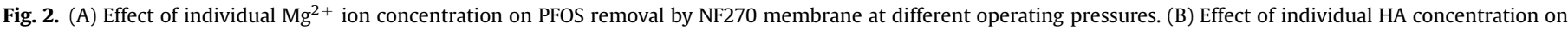
PFOS removal by NF270 membrane at different operating pressures. Experimental condition: $\mathrm{pH}=7 \pm 0.5$; temperature $=(25 \pm 0.5)^{\circ} \mathrm{C}$.

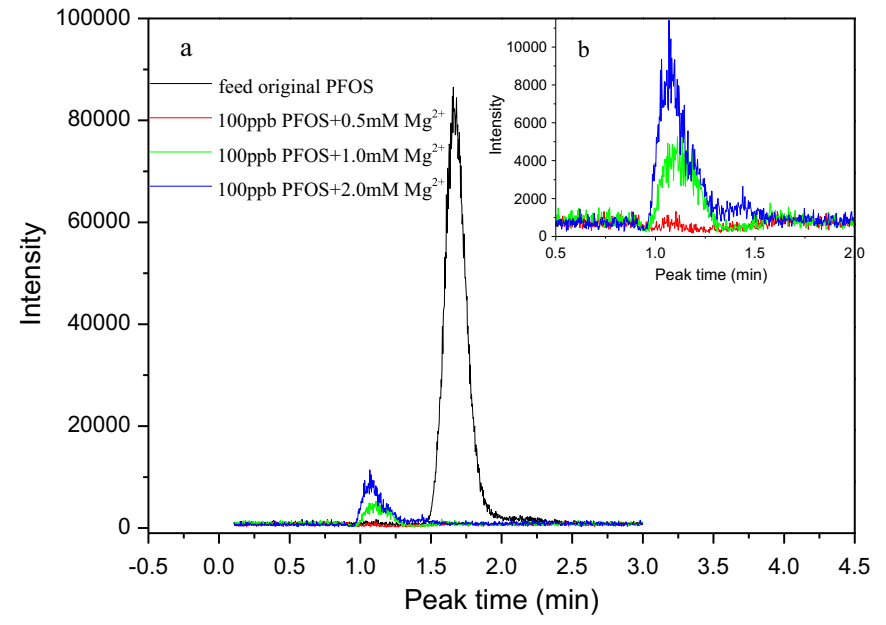

Fig. 3. PFOS peak change with the $\mathrm{Mg}^{2+}$ concentration. (a) the peak of feed origin PFOS with different $\mathrm{Mg}^{2+}$ concentration, (b) the complexation peak of PFOS with $\mathrm{Mg}^{2+}$ at different $\mathrm{Mg}^{2+}$ concentration.

Table 1

The zeta of $\mathrm{Mg}^{2+} / \mathrm{HA}$ concentration on NF270 membrane surface.

\begin{tabular}{lll}
\hline Feed system & Concentration value & $\begin{array}{l}\text { Zeta potential } \\
(\mathbf{m V})\end{array}$ \\
\hline Virgin NF270 membrane & - & -33.6 \\
& 0 & -34.2 \\
$100 \mathrm{ppb}$ PFOS + individual $\mathrm{Mg}^{2+}$ & 0.1 & -32.8 \\
Ion (mmol/L) & 0.5 & -30.4 \\
& 1 & -28.6 \\
& 1.5 & -27.2 \\
& 2 & -25.8 \\
$100 \mathrm{ppb}$ PFOS + individual $\mathrm{HA}(\mathrm{mg} /$ & 10 & -37.4 \\
$\mathrm{~L})$ & 5 & -39.5 \\
& 15 & -40.8 \\
$100 \mathrm{ppb}$ PFOS $+10 \mathrm{mg} / \mathrm{L} \mathrm{HA}+1 \mathrm{mM}$ & - & -41.6 \\
$\mathrm{Mg}^{2+}$ & & -31.5 \\
\hline
\end{tabular}

PFOS feed solution (100 ppb) on the separation performance was investigated at different operating pressures and shown in Fig. 4.

As shown in Fig. 4, it can be seen that the co-existence of $\mathrm{Mg}^{2+}$ and HA improves the PFOS rejection efficiency comparing to single
Table 2

The adsorption data of PFOS on NF270 membrane surface.

\begin{tabular}{lc}
\hline $\mathrm{Mg}^{2+}$ concentration(mmol/L) & The adsorption data $\left(\mathrm{ng} / \mathrm{cm}^{2}\right)$ \\
\hline 0 & 8.36 \\
0.1 & 11.84 \\
0.5 & 12.32 \\
1.0 & 18.65 \\
1.5 & 20.04 \\
2.0 & 23.87 \\
\hline
\end{tabular}

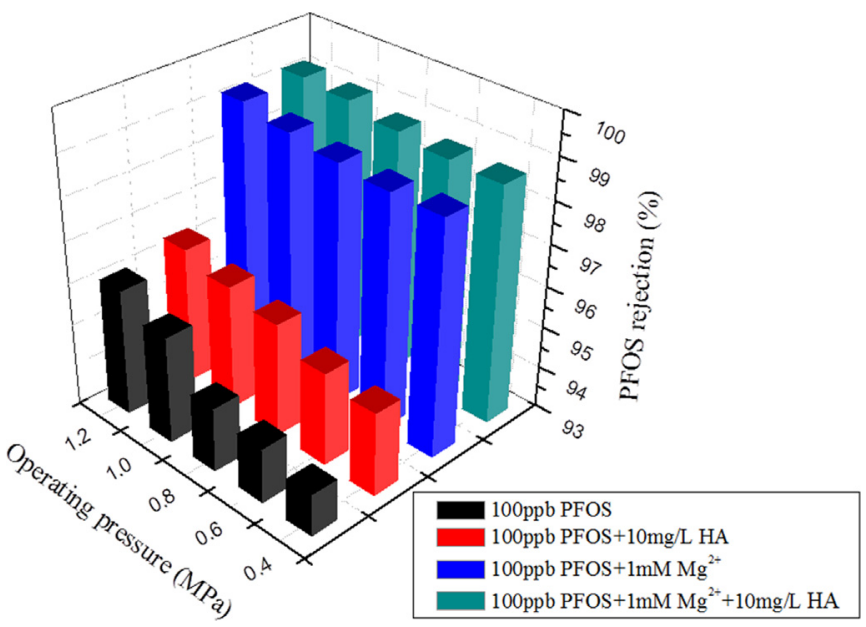

Fig. 4. Influence of the co-existing presence of $\mathrm{Mg}^{2+}$ ion and $\mathrm{HA}$ on PFOS rejection at different operating pressures. Experimental condition: $\mathrm{pH}=7 \pm 0.5$; temperature $=(25 \pm 0.5){ }^{\circ} \mathrm{C}$

HA system. The effect of co-existence and single $\mathrm{Mg}^{2+}$ on PFOS rejection are almost the same with $98 \%$ removal efficiency. It indicates $\mathrm{Mg}^{2+}$ ion plays an important in PFOS removal than HA. PFOS molecule size increases owing to the bridge between $\mathrm{Mg}^{2+}$ and PFOS, HA molecule. $\mathrm{Mg}^{2+}$ can interact with HA and form metal-humic complexes consistent with a previous study [40]. As shown in Table 1 , the co-existence of opposite electricity $\mathrm{Mg}^{2+}$ and $\mathrm{HA}$ can result in the charge screening, the zeta increase comparing to individual HA corresponding to the decrease in electrostatic repulsion between the membrane surface and HA. The adsorbance is little change (from 18.65 to $18.23 \mathrm{ng} / \mathrm{cm}^{2}$ ) than that in the individual $1 \mathrm{mM} \mathrm{Mg}^{2+}$ existence. It furthermore shows that sieving mechanism is main in PFOS removal. 


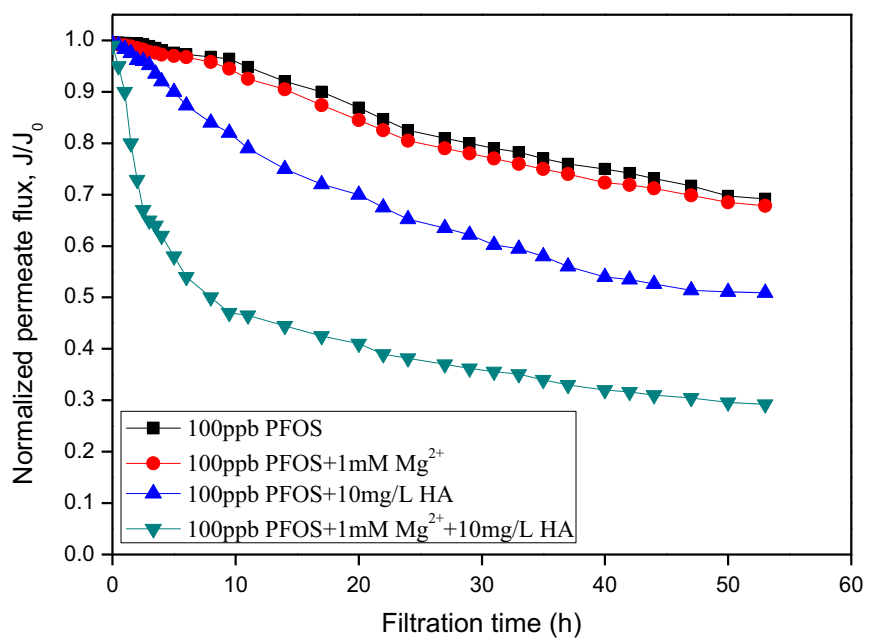

Fig. 5. The normalized permeate flux as a function of filtration time with different feed systems. Experimental condition: $\mathrm{pH}=7 \pm 0.5$; temperature $=(25 \pm 0.5)^{\circ} \mathrm{C}$; operating pressure $=0.8 \mathrm{MPa}$.

\subsection{Membrane fouling and permeate flux performance}

Permeate flux is known to be dependent on the presence of HA and $\mathrm{Mg}^{2+}$ ion in the feed solution, monitoring the flux change is essential towards assessing membrane performance. Different feed solution were tested at $\mathrm{pH} 7$ and an operating pressure of $0.8 \mathrm{MPa}$, and the resultant fluxes as a function of time are presented in Fig. 5.

A slight reduction in permeate flux was observed when $1 \mathrm{mM}$ $\mathrm{Mg}^{2+}$ ion were added to the feed solution when compared with a system containing PFOS only. By contrast, 50\% decline was observed when $10 \mathrm{mg} / \mathrm{L}$ HA was added along with PFOS. A more significant reduction, by $70 \%$, was apparent when both HA and $\mathrm{Mg}^{2+}$ ion were present in the feed solution. The results suggest that the added $\mathrm{Mg}^{2+}$ ion could act as effective bridging reagents in promoting intermolecular adhesion between the HA molecules and the membrane surface, thereby leading to a more severe membrane fouling. A schematic diagram illustrating fouling for the $\mathrm{Mg}^{2+}$ and PFOS on the membrane surface is illustrated in Fig. 6 . Comparing to single PFOS (Fig. 6a), from Fig. $6 \mathrm{~b}$ it can be seen that the $\mathrm{Mg}^{2+}$ can act as the bridge both PFOS and membrane material, and there exists some species such as PFOS-Mg, PFOS-Mg-PFOS, and PFOS-Mg-membrane on the membrane surface. In the presence of HA, owing to humic macromolecules have a flat linear configuration, HA forms a much looser fouling layer caused by the long range of double layer repulsion (see Fig. 6c). After the addition of $\mathrm{Mg}^{2+}$, owing to double layer compression and charge screening the charges of the membrane surface and humic macromolecules are reduced, which resulted in the decrease in electrostatic repulsion between the membrane surface and HA. Correspondingly, HA deposition onto the membrane surface is increased corresponding to a thick deposit layer. HA macromolecules become coiled and spherical due to reduced inter electrostatic repulsion [40]. Hence formed a more compact fouling layer (shown in Fig. 6d) with higher resistance [32,41], which resulted in further permeate flux reduction.

Fig. 7 presents the SEM images of the virgin and fouled NF270 membranes with different feed solution. The fouled membrane subjected to $100 \mathrm{ppb}$ PFOS solution and virgin membranes featured relatively uniform and smooth membrane surfaces (Fig. 7a and b). By contrast, particle deposits were observed on the fouled membrane subjected when a $1 \mathrm{mM} \mathrm{Mg}^{2+}$-containing feed solution was used (Fig. 7c). As predicted above, a cake layer feature (a)

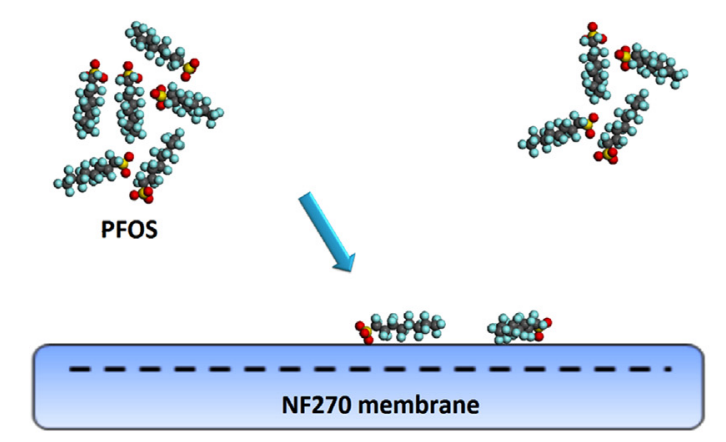

(c)

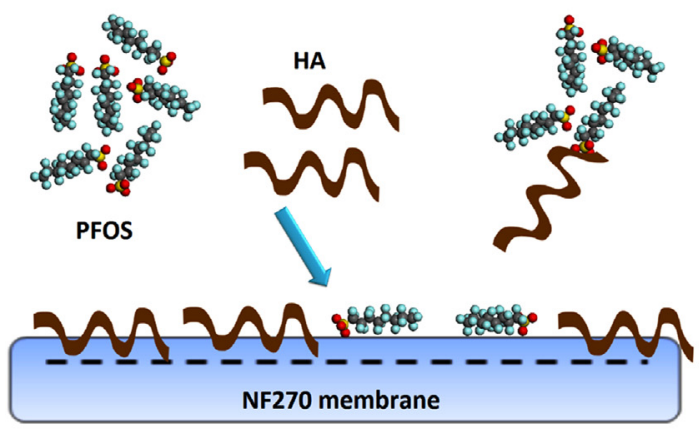

(b)

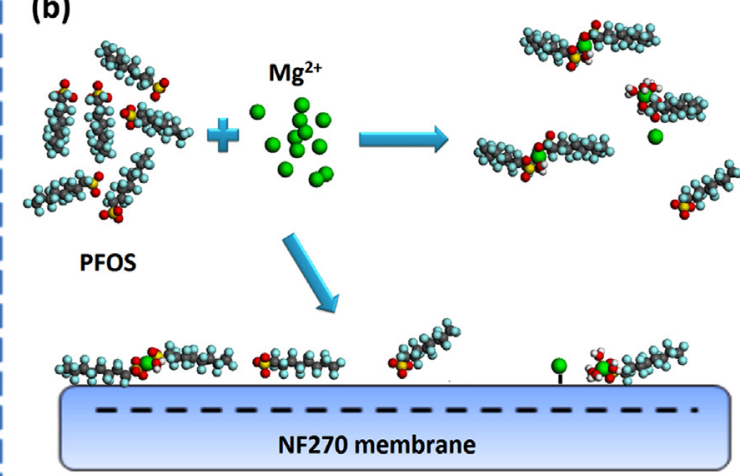

(d)

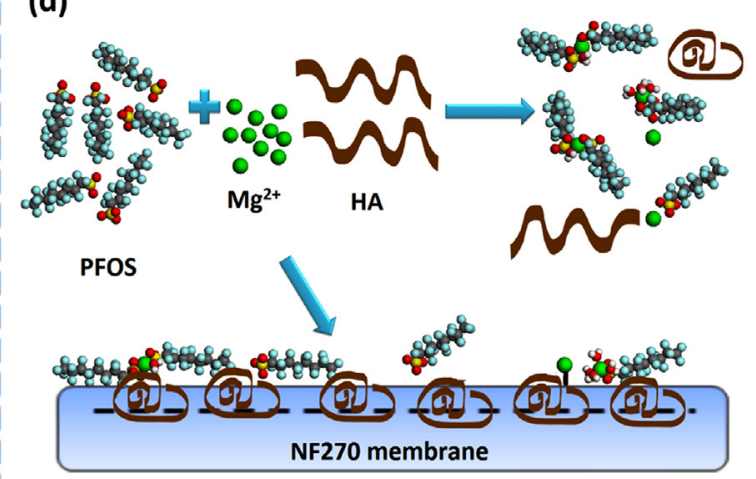

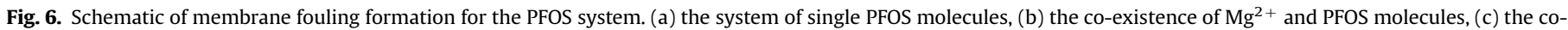
existence of HA and PFOS molecules, (d) the co-existence of $\mathrm{Mg}^{2+}$, HA and PFOS molecules. 

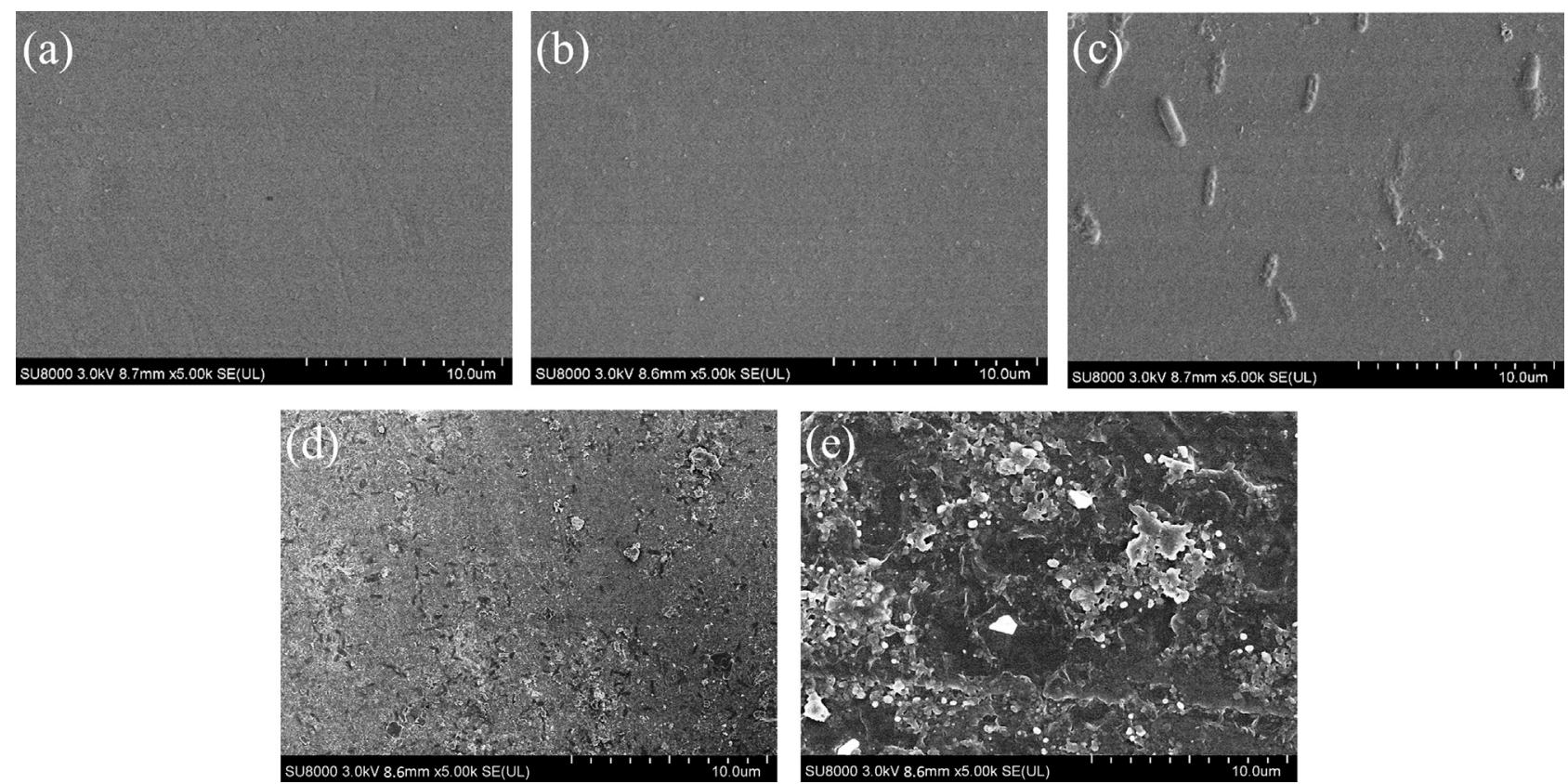

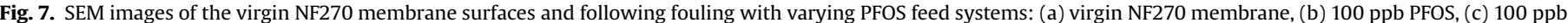
PFOS-1 mM Mg${ }^{2+}$, (d) 100 ppb PFOS-10 mg/L HA, and (e) 100 ppb PFOS- $1 \mathrm{mM} \mathrm{Mg}^{2+}-10 \mathrm{mg} / \mathrm{L}$ HA.

developed on the membrane surface when HA was present in the feed solution, as shown in Fig. $7 \mathrm{~d}$. When both $\mathrm{Mg}^{2+}$ and HA were added to the feed solution, an even denser cake layer was found to form on the membrane (Fig. 7e). For both cases where HA was added to the feed solution, the observed morphological features are consistent with the significant reduction in the permeate flux as measured previously. This further suggests that $\mathrm{Mg}^{2+}$ ion act as intermolecular bridges. Moreover, the charge neutralization capacity of $\mathrm{Mg}^{2+}$ ion can enhance the cross-linkage between the PFOS and the membrane surface, which in turn results in more pronounced membrane fouling [42].

\subsection{Mechanism analysis}

To better understand the mechanism by which $\mathrm{Mg}^{2+}$ leads to increased PFOS rejection, we modeled the interaction of PFOS and $\mathrm{Mg}^{2+}$ using DFT. The magnesium ion saturated with six water molecules [i.e., $\mathrm{Mg}^{2+}\left(\mathrm{H}_{2} \mathrm{O}\right)_{6}$ state] is the stable species in the aquatic environment. To ensure the six-fold coordination of magnesium ion, PFOS- $\mathrm{Mg}^{+}\left(\mathrm{H}_{2} \mathrm{O}\right)_{4}$ and (PFOS $)_{2} \mathrm{Mg}\left(\mathrm{H}_{2} \mathrm{O}\right)_{2}$ models were used to simulate the interaction of $\mathrm{Mg}^{2+}$ ion with one and two PFOS molecules in the aqueous solution, respectively. The calculated geometries and structural parameters of $\mathrm{Mg}^{2+}$ ionbound PFOS molecules in an aqueous solution are presented in Fig. 8 and Table 3.

Fig. $8 \mathrm{a}$ and $\mathrm{b}$ presents the structures of $\mathrm{H}_{2} \mathrm{O}$ and $\mathrm{Mg}^{2+}\left(\mathrm{H}_{2} \mathrm{O}\right)_{6}$. Frontier orbital analysis suggests that the HOMO of the anionic PFOS surfactant is primarily localized on the sulfonate headgroup (Fig. 8c), indicating that $-\mathrm{SO}_{3}^{-}$groups are the active sites that bind with the positively charged $\mathrm{Mg}^{2+}$ ion. This is consistent with Johnsons' density functional calculation that negatively charged PFOS head group is owing to the main sulfonate group [43]. Based on DFT analysis, the formation of a PFOS- $\mathrm{Mg}^{+}\left(\mathrm{H}_{2} \mathrm{O}\right)_{4}$ configuration, which corresponds to the complex of $\mathrm{Mg}^{2+}$ with one PFOS molecule (Fig. 8d), generates an increase in the molecular polarity, $\mu$, from 22.8 to 31.2 Debye, which could potentially result in increased interaction with the membrane surface. The $\mathrm{Mg}^{2+}$ ion may bind one or two PFOS anion to yield a two bridging structures according to the following reaction, respectively:
PFOS $^{-}+\mathrm{Mg}^{2+}\left(\mathrm{H}_{2} \mathrm{O}\right)_{6} \rightarrow$ PFOS- $\mathrm{Mg}^{+}\left(\mathrm{H}_{2} \mathrm{O}\right)_{4}+2 \mathrm{H}_{2} \mathrm{O}$,

$\Delta \mathrm{G}^{0}=-656.80 \mathrm{~kJ} / \mathrm{mol}$

$2 \mathrm{PFOS}^{-}+\mathrm{Mg}^{2+}\left(\mathrm{H}_{2} \mathrm{O}\right)_{6} \rightarrow$ PFOS- $\mathrm{Mg}\left(\mathrm{H}_{2} \mathrm{O}\right)_{2}-\mathrm{PFOS}+4 \mathrm{H}_{2} \mathrm{O}$,

$\Delta \mathrm{G}^{0}=-1001.55 \mathrm{~kJ} / \mathrm{mol}$

The Gibbs free energy changes of Eqs. (3) and (4) are $-656.80 \mathrm{~kJ} / \mathrm{mol}$ and $-1001.55 \mathrm{~kJ} / \mathrm{mol}$, respectively, based on the calculation of Gibbs free enthalpy and Gibbs free entropy (shown in Table 3). The free energy changes were all negative suggesting favorable formation of $\mathrm{Mg}^{2+}$-bound PFOS species (i.e., PFOS$\mathrm{Mg}^{+}\left(\mathrm{H}_{2} \mathrm{O}\right)_{4}$ and (PFOS $)_{2} \mathrm{Mg}\left(\mathrm{H}_{2} \mathrm{O}\right)_{2}$. Since $\Delta \mathrm{G}^{0}$ of Eq. (4) is significantly more negative than that of Eq. (3), PFOS- $\mathrm{Mg}\left(\mathrm{H}_{2} \mathrm{O}\right)_{2}-$ PFOS is indeed the most stable species in the presence of $\mathrm{Mg}^{2+}$, i.e., $\mathrm{Mg}^{2+}$ ion can easily bridge two PFOS anion by generating an effective attraction at $\mathrm{Mg}-\mathrm{O}(\mathrm{S})$ distances. This attraction is sufficiently strong to link the PFOS molecules and induce the formation of a magnesium-bridging-like PFOS-Mg-PFOS configuration (Fig. 8e). As a result, there is an increase in PFOS molecule size from 12.8 to $27.0 \AA$ (see Table 3 ). The increase in molecular size correlates with the improved PFOS removal efficiency observed. It is suggested that size exclusion play an important in PFOS separation mechanism operating in the NF270 membranes.

Meanwhile, we further investigate the interaction of the $\mathrm{Mg}^{2+}$ and NF 270 membrane material, here we simplify NF270 membrane material structure mainly including active groups of the $\mathrm{COOH}$ and $\mathrm{NH}_{2}$ (shown in Fig. 8f). From microscope view applying DFT theory we calculate the interaction of $\mathrm{Mg}^{2+}$ and $\mathrm{COOH}$ and $\mathrm{NH}_{2}$ of $\mathrm{NF} 270$ membrane material, corresponding configuration are shown in Fig. $8 \mathrm{~g}$ and $\mathrm{h}$, and related reaction are as follows, respectively.

$\mathrm{Mg}^{2+}\left(\mathrm{H}_{2} \mathrm{O}\right)_{6}+-\mathrm{COOH} \rightarrow \mathrm{COOH}-\mathrm{Mg}^{2+}\left(\mathrm{H}_{2} \mathrm{O}\right)_{5}+\mathrm{H}_{2} \mathrm{O}$,

$\Delta \mathrm{G}^{0}=-50.00 \mathrm{~kJ} / \mathrm{mol}$

$\mathrm{Mg}^{2+}\left(\mathrm{H}_{2} \mathrm{O}\right)_{6}+-\mathrm{NH}_{2} \rightarrow \mathrm{NH}_{2}-\mathrm{Mg}^{2+}\left(\mathrm{H}_{2} \mathrm{O}\right)_{5}+\mathrm{H}_{2} \mathrm{O}, \Delta \mathrm{G}^{0}=-96.25 \mathrm{~kJ} /$

mol

$\mathrm{Mg}^{2+}\left(\mathrm{H}_{2} \mathrm{O}\right)_{6}+\mathrm{PFOS}^{-}+-\mathrm{NH}_{2} \rightarrow$ PFOS $-\mathrm{Mg}^{+}\left(\mathrm{H}_{2} \mathrm{O}\right)_{3}-\mathrm{NH}_{2}+3 \mathrm{H}_{2} \mathrm{O}$ 


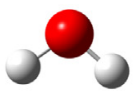

a. $\mathrm{H}_{2} \mathrm{O}$

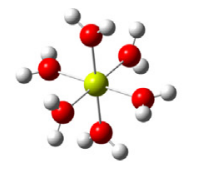

b. $\mathrm{Mg}^{2+}\left(\mathrm{H}_{2} \mathrm{O}\right)_{6}$

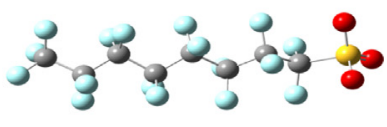

c. PFOS

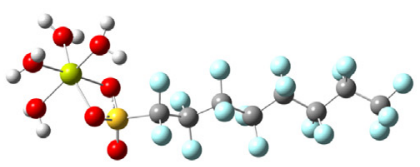

d. $\mathrm{Mg}^{+}\left(\mathrm{H}_{2} \mathrm{O}\right)_{4}$-PFOS

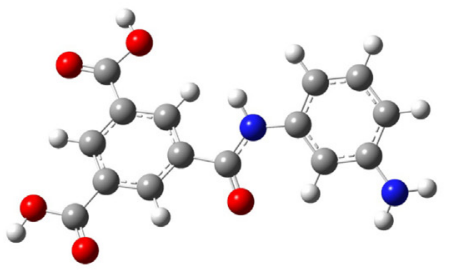

f. Simplified NF270 membrane

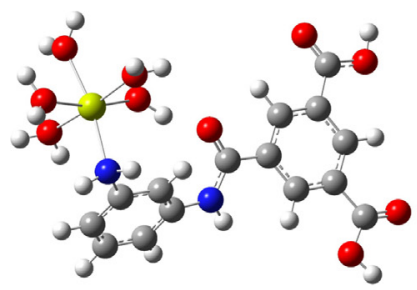

h. $\mathrm{Mg}^{2+}\left(\mathrm{H}_{2} \mathrm{O}\right)_{5}-\mathrm{NH}_{2}$ (with NF270 membrane)

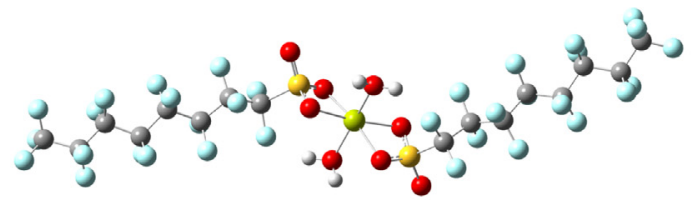

e. PFOS- $\mathrm{Mg}\left(\mathrm{H}_{2} \mathrm{O}\right)_{2}$-PFOS

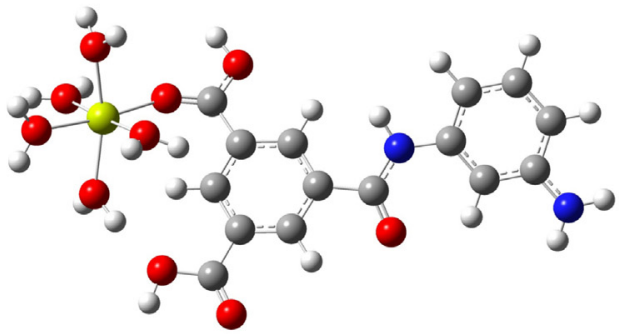

g. $\mathrm{Mg}^{2+}\left(\mathrm{H}_{2} \mathrm{O}\right)_{5}-\mathrm{COOH}$ (with NF270 membrane)

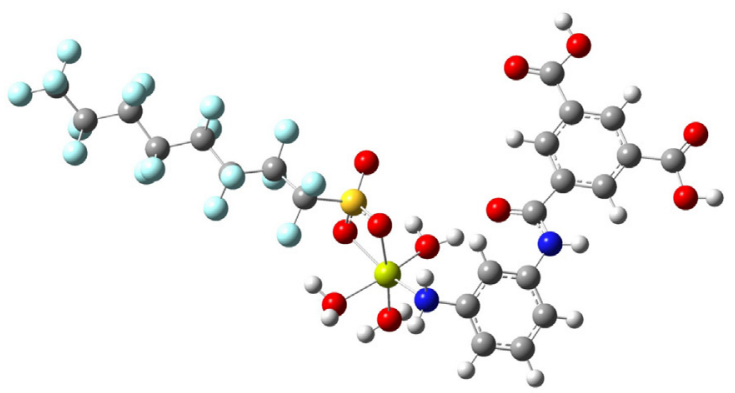

i. $\operatorname{PFOS}-\mathrm{Mg}^{+}\left(\mathrm{H}_{2} \mathrm{O}\right)_{3}-\mathrm{NH}_{2}$ (with NF270 membrane)

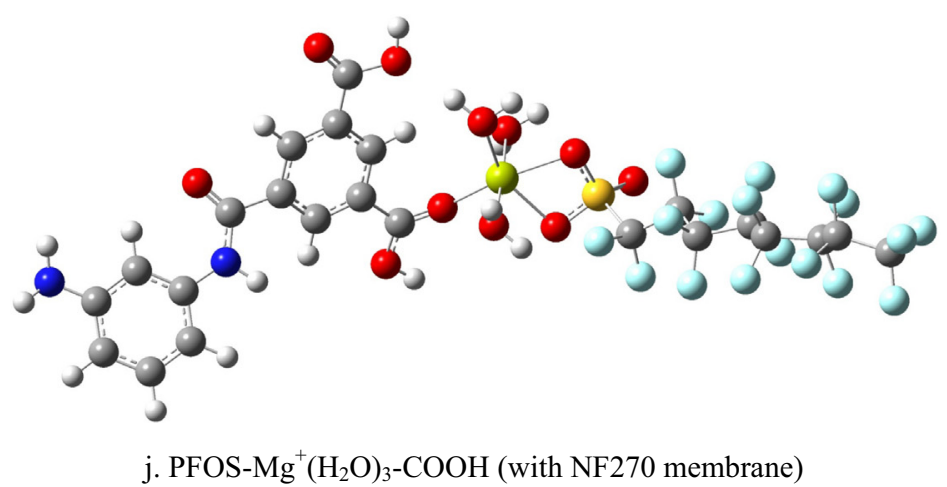

Fig. 8. (a) Structure of $\mathrm{H}_{2} \mathrm{O}$, (b) Structure of $\mathrm{Mg}^{2+}\left(\mathrm{H}_{2} \mathrm{O}\right)_{6}$, (c) Structure and HOMO orbitals of PFOS, (d) geometry of $\mathrm{Mg}^{2+}$ ion bound with one PFOS molecule, (e) geometry of $\mathrm{Mg}^{2+}$ ion bound with two PFOS molecules, (f) simulated structure of NF270 membrane, (g) geometry of $\mathrm{Mg}^{2+}$ ion bound with one COOH of NF270 membrane, (h) geometry of $\mathrm{Mg}^{2+}$ ion bound with one $\mathrm{NH}_{2}$ of NF270 membrane, (i) geometry of $\mathrm{Mg}^{2+}$ ion bound with one PFOS molecule and one $\mathrm{NH}_{2}$ of $\mathrm{NF}^{2} 70$ membrane, (j) geometry of $\mathrm{Mg}^{2+}$ ion bound with one PFOS molecule and one $\mathrm{COOH}$ of NF270 membrane. Yellow, dark yellow, red, gray, dark gray, blue and dark blue circles denote S, Mg, O, H, C, F and N atoms, respectively. The isosurface plots of the HOMO orbitals were generated with an isodensity value of 0.02 a.u. (For interpretation of the references to color in this figure legend, the reader is referred to the web version of this article.)

$\Delta \mathrm{G}^{0}=-688.15 \mathrm{~kJ} / \mathrm{mol}$

$\mathrm{Mg}^{2+}\left(\mathrm{H}_{2} \mathrm{O}\right)_{6}+\mathrm{PFOS}^{-}+-\mathrm{COOH} \rightarrow$ PFOS $-\mathrm{Mg}^{+}\left(\mathrm{H}_{2} \mathrm{O}\right)_{3}-\mathrm{COOH}+3 \mathrm{H}_{2} \mathrm{O}$ $\Delta \mathrm{G}^{0}=-662.45 \mathrm{~kJ} / \mathrm{mol}$
By DFT calculation and analysis it is also confirmed that $\mathrm{Mg}^{2+}$ ion can act to bridge between PFOS and the $-\mathrm{NH}_{2}$ and $-\mathrm{COOH}$ group of NF270 membrane structure (Figs. 8i and j, which can form new complex shown in Eqs. (7) and (8)). Based on DFT 
Table 3

DFT-calculated molecule-chain length, Gibbs free energy and Entropy.

\begin{tabular}{|c|c|c|c|}
\hline Structures & $\begin{array}{l}\text { Molecule- } \\
\text { chain length } \\
(\AA ̊)\end{array}$ & $\begin{array}{l}\text { Gibbs free en- } \\
\text { ergy }(\mathbf{k J} / \mathrm{mol})\end{array}$ & $\mathrm{S}(\mathrm{kJ} / \mathrm{mol} . \mathrm{K})$ \\
\hline $\mathrm{H}_{2} \mathrm{O}$ & - & -200602.51 & 188.85 \\
\hline $\mathrm{Mg}^{2+}\left(\mathrm{H}_{2} \mathrm{O}\right)_{6}$ & - & -1727965.08 & 507.78 \\
\hline PFOS & 12.8 & -6894319.99 & 771.43 \\
\hline PFOS-Mg ${ }^{+}\left(\mathrm{H}_{2} \mathrm{O}\right)_{4}$ & 16.1 & -8221736.86 & 1014.29 \\
\hline PFOS-Mg( $\left(\mathrm{H}_{2} \mathrm{O}\right)_{2}$-PFOS & 27.0 & 14715196.57 & 1500.45 \\
\hline $\mathrm{HA}$ & - & -2500991.08 & 547.07 \\
\hline NF270 & - & -2794305.38 & 617.02 \\
\hline $\mathrm{HA}-\mathrm{Mg}^{2+}\left(\mathrm{H}_{2} \mathrm{O}\right)_{5}$ & 13.0 & -4028357.51 & 837.21 \\
\hline $\mathrm{HA}-\mathrm{Mg}^{+}\left(\mathrm{H}_{2} \mathrm{O}\right)_{2}$-PFOS & 24.8 & -10321501.94 & 1313.38 \\
\hline $\begin{array}{l}\mathrm{COOH}-\mathrm{Mg}^{2+}\left(\mathrm{H}_{2} \mathrm{O}\right)_{5} \\
\quad \text { (withNF270 membrane) }\end{array}$ & 15.6 & -4321717.95 & 908.90 \\
\hline $\begin{array}{l}\mathrm{NH}_{2}-\mathrm{Mg}^{2+}\left(\mathrm{H}_{2} \mathrm{O}\right)_{5} \text { (with } \\
\text { NF270 membrane) }\end{array}$ & 14.2 & -4321764.21 & 903.71 \\
\hline $\begin{array}{l}\text { PFOS-Mg }{ }^{+}\left(\mathrm{H}_{2} \mathrm{O}\right)_{3}-\mathrm{NH}_{2} \text { (with } \\
\quad \text { NF } 270 \text { membrane) }\end{array}$ & 23.6 & -10815471.07 & 1395.52 \\
\hline $\begin{array}{l}\text { PFOS-Mg }{ }^{+}\left(\mathrm{H}_{2} \mathrm{O}\right)_{3}-\mathrm{COOH} \\
\quad \text { (with NF } 270 \text { membrane) }\end{array}$ & 24.8 & -10815445.38 & 1415.10 \\
\hline
\end{tabular}

analysis, the formation of the PFOS-Mg- $\mathrm{NH}_{2}$ and PFOS-Mg-COOH configuration suggest that the presence of $\mathrm{Mg}^{2+}$ can enhance PFOS-membrane interaction and PFOS rejection corresponding an increase in hydrated PFOS molecule size from 12.8 to 23.6, $24.8 \AA$, respectively. This indicates size exclusion mechanism mainly governs PFOS removal during NF270 membrane separation process.

To better prove the complexation of $\mathrm{Mg}^{2+}$ with HA and PFOS molecule, we also applied DFT to calculate the interaction between the $\mathrm{Mg}^{2+}, \mathrm{HA}$ and PFOS molecule by simulating the representative groups in the HA. The related reaction are as follows:

$\mathrm{Mg}^{2+}\left(\mathrm{H}_{2} \mathrm{O}\right)_{6}+\mathrm{HA} \rightarrow \mathrm{HA}-\mathrm{Mg}^{2+}\left(\mathrm{H}_{2} \mathrm{O}\right)_{5}+\mathrm{H}_{2} \mathrm{O}, \Delta \mathrm{G}^{0}=-3.86 \mathrm{~kJ} / \mathrm{mol}(9)$

$\mathrm{Mg}^{2+}\left(\mathrm{H}_{2} \mathrm{O}\right)_{6}+\mathrm{PFOS}^{-}+\mathrm{HA} \rightarrow \mathrm{HA}^{-\mathrm{Mg}^{+}}\left(\mathrm{H}_{2} \mathrm{O}\right)_{2}-\mathrm{PFOS}+4 \mathrm{H}_{2} \mathrm{O}$,
Table 4

The types of binding energy.

\begin{tabular}{|c|c|c|}
\hline Substance & Binding energy (eV) & The types of bonds \\
\hline \multirow[t]{3}{*}{ NF270 [44] } & 284.0 & $\mathrm{C}-\mathrm{C}$ \\
\hline & 285.5 & $\mathrm{C}=\mathrm{O}$ \\
\hline & 287.3 & $\mathrm{~N}-\mathrm{C}=\mathrm{O}$ \\
\hline \multirow[t]{4}{*}{ PFOS $[45,46]$} & 284.4 & $\mathrm{C}-\mathrm{C}$ \\
\hline & 289.7 & $\mathrm{C}-\mathrm{S}$ \\
\hline & 291.2 & $\mathrm{CF}_{2}$ \\
\hline & 292.9 & $\mathrm{CF}_{3}$ \\
\hline \multirow[t]{3}{*}{$\mathrm{PFOS}+\mathrm{MgCl}_{2}$} & 283.8 & $\mathrm{C}-\mathrm{C}$ \\
\hline & 285.1 & $\mathrm{CF}_{\mathrm{x}}$ \\
\hline & 288.1 & Unknown \\
\hline \multirow[t]{5}{*}{$\mathrm{PFOS}+\mathrm{HA}$} & 283.7 & $\mathrm{C}-\mathrm{H}, \mathrm{C}-\mathrm{N}$ \\
\hline & 248.8 & $\mathrm{C}-\mathrm{C}$ \\
\hline & 287.1 & $\mathrm{C}=\mathrm{O}$ \\
\hline & 291.8 & $\mathrm{CF}_{2}$ \\
\hline & 294.6 & $\mathrm{CF}_{3}$ \\
\hline \multirow[t]{3}{*}{$\mathrm{PFOS}+\mathrm{MgCl}_{2}+\mathrm{HA}$} & 283.6 & $\mathrm{C}-\mathrm{H}, \mathrm{C}-\mathrm{N}$ \\
\hline & 284.7 & $\mathrm{C}-\mathrm{C}$ \\
\hline & 287.7 & $\mathrm{~N}-\mathrm{C}-\mathrm{O}, \mathrm{O}-\mathrm{C}=\mathrm{O}$ \\
\hline \multirow[t]{4}{*}{ NF270 + PFOS } & 284.1 & $\mathrm{C}-\mathrm{C}$ \\
\hline & 285.7 & $\mathrm{C}=\mathrm{O}$ \\
\hline & 287.9 & $\mathrm{~N}-\mathrm{C}=\mathrm{O}$ \\
\hline & 291.1 & $\mathrm{CF}_{\mathrm{x}}$ \\
\hline \multirow[t]{3}{*}{$\mathrm{NF} 270+\mathrm{PFOS}+\mathrm{HA}+\mathrm{MgCl}_{2}$} & 284.3 & $\mathrm{C}-\mathrm{C}$ \\
\hline & 285.6 & $\mathrm{C}-\mathrm{N}, \mathrm{C}=\mathrm{O}$ \\
\hline & 287.4 & $\mathrm{~N}-\mathrm{C}-\mathrm{O}, \mathrm{O}-\mathrm{C}=\mathrm{O}$ \\
\hline
\end{tabular}

$\Delta \mathrm{G}^{0}=-635.83 \mathrm{~kJ} / \mathrm{mol}$

The calculated geometries and structural parameters of $\mathrm{Mg}^{2+}$ ion-bound - $\mathrm{COOH}$ of $\mathrm{HA}$ is presented in Fig. 9 and Table 3. It suggests that $-\mathrm{COOH}$ groups of $\mathrm{HA}$ are the active sites that bind with the positively charged $\mathrm{Mg}^{2+}$ ion. In addition, from Fig. 9c it also can be seen that $\mathrm{Mg}^{2+}$ ion can bind one PFOS molecule and $\mathrm{HA}$, which could potentially result in increased size from 12.8 to 24.8 A. Comparing to the Gibbs free energy changes of Eqs. (9) and (10) of $-3.86 \mathrm{~kJ} / \mathrm{mol}$ and $-635.83 \mathrm{~kJ} / \mathrm{mol}$ calculated from Table 3 ,

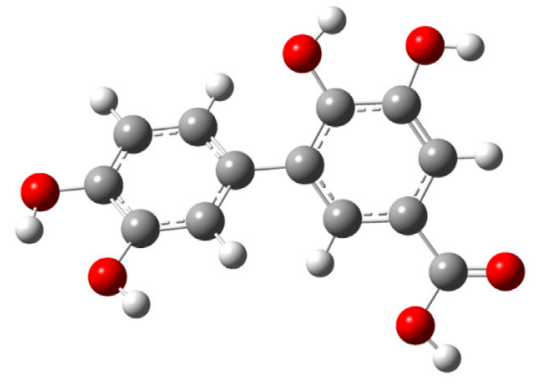

a. Simplified HA

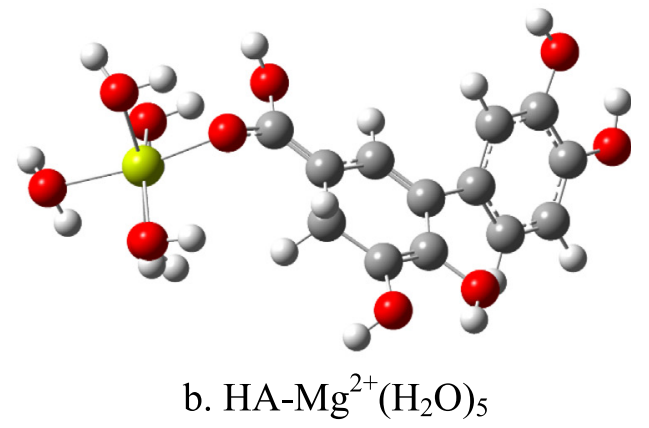

b. $\mathrm{HA}-\mathrm{Mg}^{2+}\left(\mathrm{H}_{2} \mathrm{O}\right)_{5}$

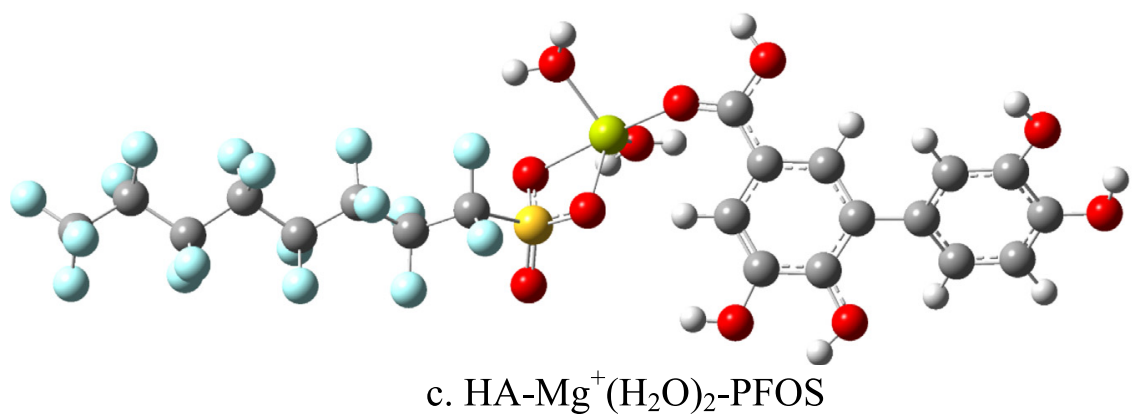

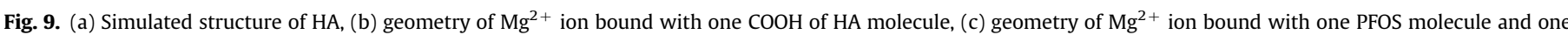

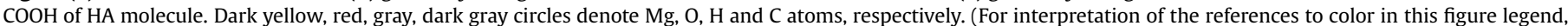
the reader is referred to the web version of this article.) 

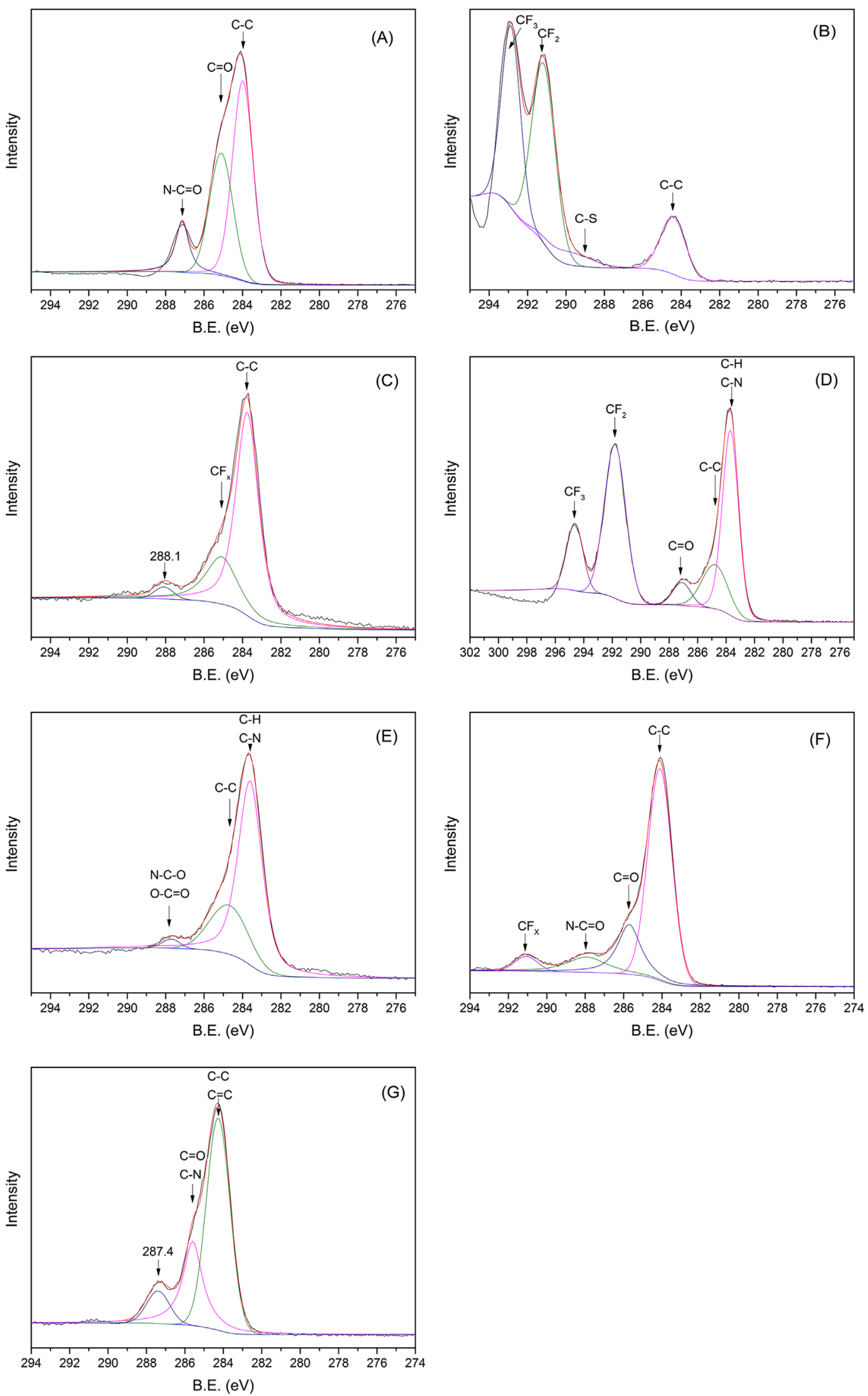

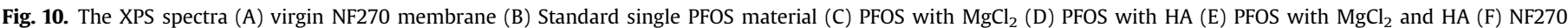
membrane with PFOS (G) NF270 membrane with $\mathrm{MgCl}_{2}$, HA and PFOS. 
we can see that $\mathrm{Mg}^{2+}$ ion can more easily bridge one PFOS anion and HA molecule than single HA molecule with larger size increase. As discussed above, the enhancement is attributed to the formation of large PFOS aggregates as instigated by $\mathrm{Mg}^{2+}$ ion-induced bridging mechanism. Taken together, these findings strongly suggest that PFOS removal by a NF270 membrane is mainly achieved through a size exclusion mechanism; the presence of $\mathrm{Mg}^{2+}$ ion has precedence than HA in contributing the PFOS removal efficiency of NF membranes.

The interaction of $\mathrm{Mg}^{2+}$, PFOS and membrane are further characterized with XPS measurement. The C 1s XPS spectra of virgin NF270 membrane and PFOS shown in Fig. 10 (A and B) was obtained from NF270 virgin membrane and standard PFOS substance, and previous types of bonds and binding energy was shown in Table 4.

The spectra change with $\mathrm{C} 1 \mathrm{~s}$ is obvious after adding $\mathrm{MgCl}_{2}$ shown in Fig. 10 (C). The $\mathrm{C}-\mathrm{C}$ peak $(283.8 \mathrm{eV})$ is negatively shifted from the binding energy $284.4 \mathrm{eV}$ and new peak $(288.1 \mathrm{eV})$ forms due to $\mathrm{Mg}^{2+}$ bonded to PFOS molecules. Because the $\mathrm{Mg}^{2+}$ ion has several positive site attracting and chemically bonding the negative $\mathrm{SO}_{3}^{-}$groups of PFOS molecules [47,48], the peak of $\mathrm{CF}_{2}$ and $\mathrm{CF}_{3}$ have shifted to $285.1 \mathrm{eV}$. The $-\mathrm{SO}_{3}-\mathrm{Mg}$ groups conceal the weak C$S$ bonds might play an important role during the membrane filtration. The addition of HA into the solution (Fig. 10 D), comparing to Fig. $10 \mathrm{~B}$ the spectra has significant changes. The new binding energy at $283.7 \mathrm{eV}$ might be the $\mathrm{C}-\mathrm{H}$ bonds or the $\mathrm{C}-\mathrm{N}$ bonds from $\mathrm{HA}$, the $\mathrm{C}-\mathrm{C}$ bonds and the $\mathrm{C}=\mathrm{O}$ bonds at $284.8 \mathrm{eV}$ and $287.1 \mathrm{eV}$, respectively; the $\mathrm{CF}_{2}$ bonds and $\mathrm{CF}_{3}$ bonds are positively shifted to $291.8 \mathrm{eV}$ and $294.6 \mathrm{eV}$, respectively. After adding both $\mathrm{Mg}^{2+}$ and $\mathrm{HA}$ into the solution (Fig. $10 \mathrm{E}$ ), the $\mathrm{C}-\mathrm{H}$ bonds or $\mathrm{C}-\mathrm{N}$ bond is negatively shifted to $283.6 \mathrm{eV}$, the $\mathrm{C}-\mathrm{C}$ bonds is negatively shifted to $284.7 \mathrm{eV}$, the $\mathrm{N}-\mathrm{C}-\mathrm{O}$ bonds or $\mathrm{O}-\mathrm{C}=\mathrm{O}$ bonds is at $287.7 \mathrm{eV}$ from HA functional groups. It is consistent with previous researches that hydrophobic interaction between the HA and PFOS in the solution might attribute to the hydrophobic properties of the $\mathrm{C}-\mathrm{F}$ chains in PFOS molecules $[49,50]$. The hydrogen bonds between two negative charge molecules would attract $-\mathrm{SO}_{3}$ group of PFOS molecules and oxygen-containing functional groups on HA. These two interactions would result in connecting anionic molecules owing to electrostatic repulsion. The $\mathrm{Mg}^{2+}$ could form PFOS-Mg-HA compounds by connecting with both PFOS molecules and HA. It is assumed that the Mg-PFOS compound is the core of PFOS-Mg-HA compounds with the disappearance of $\mathrm{C}-\mathrm{F}$ bonds in Fig. $10 \mathrm{D}$. The $\mathrm{C}-\mathrm{F}$ bond through the hydrophobic interaction would attract HA, the carboxyl group would connect with $\mathrm{Mg}-\mathrm{SO}_{3}$ group, rich oxygen-containing functional groups would attract with each other through the hydrogen bonds. As shown in the Fig. $10 \mathrm{E}$, the $\mathrm{C}-\mathrm{N}$ bond, the $\mathrm{N}-\mathrm{C}-\mathrm{O}$ bond and carboxyl have proven that the HA is surround the Mg-PFOS compounds and it might form the hydrophobic interaction. Hydrogen bond and electrovalent bond could form large size compounds that would be easily rejected by membrane surface.

Comparing to the spectra of virgin NF270 membrane (Fig. 10 A), only adding single PFOS (shown in Fig. $10 \mathrm{~F}$ ), the $\mathrm{C}=\mathrm{O}$ bond of membrane is positively shifted from $285.5 \mathrm{eV}$ to $285.7 \mathrm{eV}$ and the $\mathrm{N}-\mathrm{C}=\mathrm{O}$ binding energy at $287.3 \mathrm{eV}$ is shifted to $287.9 \mathrm{eV}$, the $\mathrm{CF}_{3}$ bonds $(292.2 \mathrm{eV})$ disappears and $\mathrm{CF}_{x}$ peak $(291.2 \mathrm{eV})$ is shifted to $291.1 \mathrm{eV}$. Hydrophobic interaction between the NF270 membrane and PFOS can attribute to the hydrophobic properties of the $\mathrm{C}-\mathrm{F}$ chains in PFOS molecules [51]. The $-\mathrm{NH}^{+}$groups in the membrane materials could reduce the electrostatic repulsion which would attract $-\mathrm{SO}_{3}$ group to the membrane surface [46]. Moreover, according to the previous report by Wang et al. [52], it is concluded that the hydrophobic interaction between the membrane surface and PFOS molecule is much stronger than electrostatic repulsion. The above all changes demonstrate the existence of PFOS molecules are chemically bonds to the membrane surface in consistent with the mechanisms that PFOS can adsorbed on negative charge membrane surface. After the co-existence of three materials of PFOS, $\mathrm{MgCl}_{2}$ and $\mathrm{HA}$ in the solution with NF270 membrane (Fig. $10 \mathrm{G}$ ), all three types bonds are negatively shifted to $284.3 \mathrm{eV}$, $285.6 \mathrm{eV}$ and $287.4 \mathrm{eV}$, respectively. This phenomenon could attribute to the negative charge membrane surface. The $-\mathrm{NH}^{+}$ groups on membrane surface could attract HA molecules with PFOS-Mg-HA compound, and the hydrogen bond would connect both oxygen-containing functional groups during the filtration [52-54]. Moreover, the $\mathrm{Mg}^{2+}$ ion in the solution would adsorb onto the membrane surface attracting the negative charge compound of PFOS-Mg-HA. It is assumed that $\mathrm{Mg}^{2+}$ play a bridging role connecting both membrane surface, PFOS molecules and HA. The above changes could influence the binding energy and the rejection of membrane.

\section{Conclusion}

In summary, the effective removal of PFOS by a NF270 membrane in varying feed condition comprising $\mathrm{Mg}^{2+}$ ion and HA was demonstrated. The presence of $\mathrm{Mg}^{2+}$ improved PFOS rejection efficiencies, up to $99.4 \%$ with relatively little change in the overall flux through the system. By contrast, only minimal improvement in the PFOS rejection efficiency was obtained in the presence of HA in the PFOS feed solution while overall flux, and hence system efficiency, was significantly reduced. The addition of $\mathrm{Mg}^{2+}$ along with HA to the feed solution again led to increased rejection efficiency of the PFOS. DFT analysis suggested that the improvement of PFOS removal could be attributed to the bridging effects as promoted by the presence of $\mathrm{Mg}^{2+}$ ion. According to the Gibbs free energy changes of $-1001.55 \mathrm{~kJ} / \mathrm{mol}$ and $-656.80 \mathrm{~kJ} / \mathrm{mol}$ based on the second law of thermodynamics, $\mathrm{Mg}^{2+}$ ion can more easily neutralize two PFOS anion than one PFOS anion. In addition, the interaction between $\mathrm{Mg}^{2+}$ and the carboxylic group of $\mathrm{HA}$ molecule, carboxylic or amino group of NF270 membrane were also calculated by DFT. Corresponding DFT structures and calculation parameters of $\mathrm{Mg}^{2+}$ with different groups were obtained. These DFT findings indicate that the molecular size plays an important in PFOS removal by the NF270 membrane. These results highlight the potential of NF270 membrane separation for PFOS removal in the co-existence of $\mathrm{Mg}^{2+}$ and $\mathrm{HA}$ from surface water.

\section{Acknowledgments}

This work was supported by the National Natural Science Foundation of China (No. 21176245 and 21476248), the National Science and Technology Support Program of China (No.2012BAJ25B02 and 2012BAJ25B06), and Youth Innovation Promotion Association CAS are gratefully acknowledged by the authors.

\section{References}

[1] A.G. Pual, K.C. Jones, A.J. Sweetman, A first global production, emission, and environmental inventory for perfluorooctane sulfonate, Environ. Sci. Technol. 43 (2009) 386-392.

[2] Y.T. Tsai, A.Y.C. Lin, Y.H. Weng, K.C. Li, Treatment of perfluorinated chemicals by electro-microfiltration, Environ. Sci. Technol. 44 (2010) 7914-7920.

[3] B.F. Scott, C. Spencer, S.A. Mabury, D.C.G. Muir, Poly and perfluorinated carboxylates in north american precipitation, Environ. Sci. Technol. 40 (2006) 7167-7174.

[4] L.M. Yim, S. Taniyasu, L.W.Y. Yeung, G. Lu, L. Yang, Y. Jin, P.K.S. Lam, K. Kannan, N. Yamashita, Perfluorinated compounds in tap water from china and several other countries, Environ. Sci. Technol. 43 (2009) 4824-4829.

[5] Y.W. Wang, J.J. Fu, T.H. Wang, Y. Liang, Y.Y. Pan, Y.Q. Cai, G.B. Jiang, Distribution 
of perfluorooctane sulfonate and other perfluorochemicals in the ambinent environment around a manufacturing facility in China, Environ. Sci. Technol. 44 (2010) 8062-8067.

[6] K.L. Zhang, J. Huang, G. Yu, Q.W. Zhang, S.B. Deng, B. Wang, Destruction of perfluorooctane sulfonate (PFOS) and perfluorooctanoic acid (PFOA) by ball milling, Environ. Sci. Technol. 47 (2013) 6471-6477.

[7] X.N. Li, S. Chen, X. Quan, Y.B. Zhang, Enhanced adsroption of PFOA and PFOS on multiwalled carbon nanotubes under electrochemical assistance, Environ. Sci. Technol. 45 (2011) 8498-8505.

[8] J.M. Armitage, U. Schenker, M. Scheringer, J.W. Martin, M. Macleod, L. T. Cousins, Modeling the global fate and transport of perfluorooctane sulfonate (PFOS) and precursor compounds in relation to temporal trends in wildlife exposure, Environ. Sci. Technol. 43 (2009) 9274-9280.

[9] O. Quinones, S. Snyder, Occurrence of perfluoroalkyl carboxylates and sulfonates in drinking water utilities and related waters from the United States, Environ. Sci. Technol. 43 (2009) 9089-9095.

[10] S.B. Deng, Q. Zhou, G. Yu, J. Huang, Q. Fan, Removal of perfluorooctanoate from surface water by polyaluminium chloride coagulation, Water Res. 45 (2011) $1774-1780$.

[11] C. Eschauzier, E. Beerendonk, P.S. Veenendaal, P.D. Voogt, Impact of treatment process on the removal of perfluoroalkyl acids from the drinking water production chain, Environ. Sci. Technol. 46 (2012) 1708-1715.

[12] F. Xiao, M.F. Simcik, J.S. Gulliver, Mechanisms for removal of perfluorooctane sulfonate (PFOS) and perfluorooctanoate (PFOA) from drinking water by conventional and enhanced coagulation, Water Res. 47 (2013) 49-56.

[13] C.Y. Tang, Q.S. Fu, C.S. Criddle, J.O. Leckie, Effect of flux (transmembrane pressure) and membrane properties on fouling and rejection of reverse osmosis and nanofiltration membranes treating perfluorooctane sulfonate containing wastewater, Environ. Sci. Technol. 41 (2007) 2008-2014.

[14] E.S. Darling, M. Reinhard, Nanofiltration for trace organic contaminant removal: structure, solution, and membrane fouling effects on the rejection of perfluorochemicals, Environ. Sci. Technol. 42 (2008) 5292-5297.

[15] X.F. Hang, X.R. Chen, J.Q. Luo, W.F. Cao, Y.H. Wan, Removal and recovery of perfluorooctanoate from wastewater by nanofiltration, Sep. Purif. Technol. 145 (2015) 120-129.

[16] J. Gao, S.P. Sun, W.P. Zhu, T.S. Chung, Chelating polymer modified P84 nanofiltration (NF) hollow fiber membranes for high efficient heavy metal removal, Water Res. 63 (2014) 252-261.

[17] Y. Zhang, S. Zhang, T.S. Chung, Nanometric graphene oxide framework mem branes with enhanced heavy metal removal via nanofiltration, Environ. Sci. Technol. 49 (2015) 10235-10242.

[18] T.D. Appleman, C.P. Higgins, O. Quinones, B.J. Vanderford, C. Kolstad, J. C. Holady, E.R.V. Dickenson, Treatment of poly- and perfluoroalkyl substances in US full-scale water treatment systems, Water Res. 51 (2014) 246-255.

[19] T.D. Appleman, E.R.V. Dickenson, C. Bellona, C.P. Higgins, Nanofiltration and granular activated carbon treatment of perfluoroalkyl acids, J. Hazard. Mater 260 (2013) 740-746.

[20] J.H. Yan, J.M. Li, Q. Ye, K. Li, Concentration and exports of solutes from surface runoff in Houzhai Karst Basin, southwest China, Chem. Geol. 304-305 (2012) $1-9$.

[21] C.W. Zhao, J. Zhang, G.Z. He, T. Wang, D.Y. Hou, Z.K. Luan, Perfluorooctane sulfonate removal by nanofiltration membrane the role of calcium ion, Chem. Eng. J. 233 (2013) 224-232.

[22] C.Y. Tang, Q. Shiang, Fu, D. Gao, C.S. Criddle, J.O. Leckie, Effect of solution chemistry on the adsorption of perfluorooctane sulfonate onto mineral surfaces, Water Res. 44 (2010) 2654-2662.

[23] F. Wang, K. Shih, Adsorption of perfluorooctanesulfonate (PFOS) and perfluorooctanoate (PFOA) on aluminia: influence of solution $\mathrm{pH}$ and cation, Water Res. 45 (2011) 2925-2930.

[24] N.H. Subramanian, P. Manigandan, A. Wille, G. Radhakrishnan, Determination of perfluorooctanoate and perfluorooctanesulfonate in water matrices by inline matrix elimination liquid chromatography with reversed phase separation and suppressed conductivity detection, J. Chromatogr. Sci. 49 (2011) 603-609.

[25] J. Cheng, C.D. Vecitis, H. Park, B.T. Mader, M.R. Hoffmann, Sonochemical degradation of perfluorooctane sulfonate (PFOS) and perfluorooctanoate (PFOA) in groundwater: kinetic effects of matrix inorganics, Environ. Sci. Technol. 44 (2010) 445-450.

[26] X.L. Lu, S.R.V. Castrillon, D.L. Shaffer, J. Ma, M. Elimelech, In situ surface chemical modification of thin-film composite forward osmosis membranes for enhanced organic fouling resistance, Environ. Sci. Technol. 47 (2013) 12219-12228.

[27] J.H. Shao, J. Hou, H.C. Song, Comparison of humic acid rejection and flux decline during filtration with negatively charged and uncharged ultrafiltration membranes, Water Res. 45 (2011) 473-482.

[28] C.Y. Tang, T.H. Chong, A.G. Fane, Colloidal interaction and fouling of NF and RO membranes: A review, Adv. Colloid Interface 164 (2011) 126-143.

[29] C.P. Higgins, R.G. Luthy, Sorption of perfluorinated surfactants on sediments, Environ. Sci. Technol. 40 (2006) 7251-7256.
[30] M.M. Montero-Campillo, N. Mora-Diez, A.M. Lamsabhi, Thermodynamic stability of neutral and anionic PFOS: A Gas-Phase, n-Octanol, and water theoretical study, J. Phys. Chem. A 114 (2010) 10148-10155.

[31] M.M.M. Campillo, N.M. Diez, A.M. Lamsabhi, Thermodynamic stability of neutral and anionic PFOS: agas-phase,n-octanol,and water theoretical study, J. Phys. Chem. 114 (2010) 10148-10155.

[32] C.Y. Tang, Y.-N. Kwon, J.O. Leckie, Characterization of humic acid fouled reverse osmosis and nanofiltration membranes by transmission electron microscopy and streaming potential measurements, Environ. Sci. Technol. 41 (2007) 942-949.

[33] C.Y. Tang, Y.-N. Kwon, J.O. Leckie, Effect of membrane chemistry and coating layer on physiochemical properties of thin film composite polyamide RO and NF membranes. I. FTIR and XPS characterization of polyamide and coating layer chemistry, Desalination 242 (2009) 149-167.

[34] L. Braeken, B. Bettens, K. Boussu, P. Van der Meeren, J. Cocquyt, J. Vermant, B. Van der Bruggen, Transport mechanisms of dissolved organic compounds in aqueous solution during nanofiltration, J. Membr. Sci. 279 (2006) 311-319.

[35] L. TeMmol, W. Kern, T. Luxbacher, Zeta potential of photochemically modified polymer surfaces, Characterization of Polymer Surfaces and Thin Fllms, 132 Springer-Verlag Berlin, Berlin (2006), pp. 4-61.

[36] A.D. Becke, Density-functional thermochemistry. 3. The role of exact exchange, J. Chem. Phys. 98 (1993) 5648-5652.

[37] C.T. Lee, W.T. Yang, R.G. Parr, Development of the Colle-Salvetti correlationenergy formula into a founctional of the electron-density, Phys. Rev. B 37 (1988) 785-789.

[38] F.J. Stevenson, Humus chemistry: genesis, composition, reactions, John Wiley \& Sons, New York, 1994.

[39] S.W. Wang, J. Huang, Y. Yang, Y.M. Hui, Y.X. Ge, T.J. Larssen, G. Yu, S.B. Deng, B. Wang, C. Harman, First report of a chinese PFOS alternative overlooked for 30 years: its toxicity, persistence, adn presence in the environment, Environ. Sci. Technol. 47 (2013) 10163-10170.

[40] S. Hong, M. Elimelech, Chemical and physical aspects of natural organic matter (NOM) fouling of nanofiltration membranes, J. Membr. Sci. 132 (1997) 159-181.

[41] S.H. Yoon, C.H. Lee, K.J. Kimand, A.G. Fane, Effect of calcium ion on the fouling of nanofilter by humic acid in drinking water production, Water Res. 32 (1998) 2180-2186.

[42] L.D. Nghiem, P.J. Coleman, C. Espendiller, Mechanisms underlying the effects of membrane fouling on the nanofiltration of trace contamints, Desalination 250 (2010) 682-687.

[43] R.L. Johnsn, A.J. Anschutz, J.M. Smolen, M.F. Simcik, R.L. Penn, The adsorption of perfluorooctane sulfonate onto sand, clay, and iron oxide surfaces, J. Chem. Eng. Data 52 (2007) 1165-1170.

[44] W.R. Bowen, T.A. Doneva, Atomic force microscopy studies of membranes: effect of surface roughness on double-layer interaction and particle adhesion, J. Colloid Interface Sci. 229 (2000) 544-549.

[45] C.Y. Tang, Y.-N. Kwon, J.O. Leckie, Effect of membrane chemistry and coating layer on physiochemical properties of thin film composite polyamide RO and NF membranes: I. FTIR and XPS characterization of polyamide and coating layer chemistry, Desalination 242 (2009) 149-167.

[46] S. Dapoz, N. Betz, M.-J. Guittet, A. Le Moël, ESCA characterization of heparinlike fluoropolymers obtained by functionalization after grafting induced by swift heavy ion irradiation, Nucl. Instrum. Methods Phys. Res. Sect. B: Beam Interact. Mater. Atoms 105 (1995) 120-125.

[47] C. Hamilton, J. Lomeda, Z. Sun, J. Tour, A. Barron, Radical addition of perfluorinated alkyl iodides to multi-layered graphene and single-walled carbon nanotubes, Nano Res. 3 (2010) 138-145.

[48] Y. Zhou, B. Wen, Z. Pei, G. Chen, J. Lv, J. Fang, X. Shan, S. Zhang, Coadsorption of copper and perfluorooctane sulfonate onto multi-walled carbon nanotubes, Chem. Eng. J. 203 (2012) 148-157.

[49] F. Wang, K. Shih, Adsorption of perfluorooctanesulfonate (PFOS) and perfluorooctanoate (PFOA) on alumina: Influence of solution $\mathrm{pH}$ and cation, Water Res. 45 (2011) 2925-2930.

[50] Y. Dai, J. Niu, L. Yin, J. Xu, K. Sun, Enhanced sorption of perfluorooctane sulfonate (PFOS) on carbon nanotube-filled electrospun nanofibrous membranes, Chemosphere 93 (2013) 1593-1599.

[51] C. Xu, H. Chen, F. Jiang, Adsorption of perflourooctane sulfonate (PFOS) and perfluorooctanoate (PFOA) on polyaniline nanotubes, Colloids Surf. A: Physicochem. Eng. Asp. 479 (2015) 60-67.

[52] T. Wang, C. Zhao, P. Li, Y. Li, J. Wang, Fabrication of novel poly(m-phenylene isophthalamide) hollow fiber nanofiltration membrane for effective removal of trace amount perfluorooctane sulfonate from water, J. Membr. Sci. 477 (2015) 74-85.

[53] S.B. Deng, R.B. Bai, Adsorption and desorption of humic acid on aminated polyacrylonitrile fibers, J. Colloid Interface Sci. 280 (2004) 36-43.

[54] W.S.W. Ngah, S. Fatinathan, N.A. Yosop, Isotherm and kinetic studies on the adsorption of humic acid onto chitosan- $\mathrm{H}_{2} \mathrm{SO}_{4}$ beads, Desalination 272 (2011) 293-300. 